\title{
FisioDRUM: Serious Game em desenvolvimento
}

\author{
Gustavo Rodrigues F. Gonçalves ${ }^{1}$, Eduardo M. S. de Brito ${ }^{2}$, Thaise S. G. de Brito ${ }^{3}$ \\ ${ }^{1}$ Curso de Computação - Faculdade de Ciências Aplicadas e Sociais de Petrolina \\ (FACAPE) - Petrolina, PE - Brasil \\ ${ }^{2}$ Colegiado de Informática - Instituto Federal de Educação, Ciência e Tecnologia do \\ Sertão Pernambucano (IF SERTÃO) - Floresta, PE - Brasil
${ }^{3}$ Departamento de TI - Programa GP - Secretaria de Desenvolvimento Social, Criança e Juventude (SDSCJ) - Petrolina, PE - Brasil
gu_rodrigues13@hotmail.com, eduardo.brito@ifsertao-pe.edu.br, thaisegama@gmail.com

\begin{abstract}
Serious games" is a game category that involves training and entertainment, so that the user interacts with the machine in a more playful way without losing training which is the activitie's focus. This article presents the development of a "serious game" that seeks to assist physical therapy sessions in the treatment of deficit of strength and movements range using the musical instrument drums as a resource. The game is in the process of prototyping and it intents to combine the game with song so that the patient can perform the treatment in a funnier and more motivating way.
\end{abstract}

Resumo. "Serious games" é uma categoria de games que envolve treinamento e entretenimento, para que o usuário interaja com a máquina de uma forma mais lúdica sem perder o treinamento que é foco da atividade. Este artigo apresenta o desenvolvimento de um "serious game" que visa auxiliar as sessões de fisioterapia no tratamento de déficit de força e amplitude de movimentos usando como recurso o instrumento musical bateria. O jogo está em fase de prototipação e se propõe a combinar o jogo com a música para que o paciente possa realizar o tratamento de forma mais divertida e motivadora.

\section{Introdução}

Diante do crescimento tecnológico nos diversos ramos da ciência, a saúde tem sido uma área privilegiada quanto aos benefícios trazidos pelos implementos da computação, que auxiliam os profissionais tanto no diagnóstico preciso, na intervenção adequada, como na reabilitação [Cardoso et al. 2008].

Os Serious Games (SG) aparecem como uma boa opção para métodos alternativos pela sua adaptabilidade para cada paciente, levando em consideração suas limitações motoras e cognitivas, além da capacidade motivacional dos jogos que mantém o paciente sempre estimulado pela ideia de diversão e tratamento aliadas.

O déficit de força e amplitude de movimentos é uma lesão causada por um acidente ou doença, causando limitações físicas. A bateria é um instrumento musical que proporciona a execução de movimentos similares aos exercícios realizados nas sessões de fisioterapia para o tratamento dessa lesão. Ao tocar bateria as mãos são alternadas ocorrendo à flexão dos punhos. Realiza ainda, movimentos nos pedais que trabalham a 
dorsiflexão dos pés, proporcionando ganho de força devido a pressão realizada. Diante desse contexto, é relevante o uso da bateria para auxiliar o tratamento desse tipo de lesão.

A presente pesquisa tem o objetivo de apresentar um serious game, nomeado de FisioDRUM, que usa o instrumento musical bateria como recurso para auxiliar no tratamento fisioterapêutico de pacientes que apresentam déficit de força e amplitude de movimentos. O SG proposto encontra-se em desenvolvimento, na fase de prototipação.

A primeira etapa deste trabalho consistiu em pesquisa bibliográfica para levantamento de subsídios teóricos, seguindo de estudos das ferramentas e dispositivos disponíveis para analisar a viabilidade técnica.

Posteriormente, foram realizadas reuniões com profissionais da área de saúde, sendo uma fisioterapeuta e um educador físico, além da participação de um músico baterista que apresentou os principais movimentos praticados no instrumento para os demais profissionais, a fim de identificar os movimentos realizados ao tocar $o$ instrumento que é adotado nas sessões de fisioterapia de pacientes que realizam o tratamento proposto, identificando assim a viabilidade do projeto. Também foram realizadas entrevistas com os profissionais envolvidos para o levantamento dos requisitos, que serviram de subsídio para o desenvolvimento do protótipo.

O artigo segue a seguinte estrutura: a seção 2 apresenta os aspectos conceituais de serious games. A seção 3 apresenta a influência da música e da bateria para saúde, o desenvolvimento do protótipo é apresentado na seção 4 e na seção 5 são disponibilizadas as conclusões.

\section{Serious Games}

Os Serious Games são jogos com um propósito específico, que extrapolam a ideia de entretenimento e oferecem outros tipos de experiências, como às voltadas ao aprendizado e treinamento. Estes jogos vêm se tornando populares por oferecerem um meio motivador de aprender [Barnes et al. 2009].

De acordo com Machado, Moraes e Nunes (2009), um dos setores que tem se beneficiado dos serious games é o da medicina. Para Johnson et al. (2007) jogos para a saúde são de grande importância e servem para vários aspectos, tais como: distração do paciente em seu tratamento fisioterapêutico, condicionamento físico, treinamento de profissionais, entre outros.

A construção de serious games específicos para saúde, a presença e participação dos profissionais da área é essencial para que tais ferramentas tenham validade e possam ser amplamente utilizadas pelos usuários finais. Tal parceria tem contribuído, de forma significativa, no treinamento, educação e informação destes profissionais e de pacientes, uma vez que estas ferramentas estimulam e motivam o aprendizado dos jogadores. Diversos fatores são considerados relevantes à expansão destas aplicações: as dificuldades encontradas na obtenção de materiais, validação de produtos e treinamento de pessoal, bem como a necessidade de novas abordagens para reabilitação e ensino de hábitos saudáveis [Machado, Moraes e Nunes 2009].

\section{A Música e o instrumento musical bateria para saúde}

A música vem sendo utilizada para ajudar no tratamento de problemas de ordem física, emocional ou mental. O papel da música como agente terapêutico para auxiliar em 
diversas áreas da saúde tem despertado interesse nas últimas décadas, com pesquisadores enfatizando a importância da música no equilíbrio físico e mental do indivíduo. [Scharfer 2002, Storr 1992 e Leandro et al. 2006].

\section{Desenvolvimento do protótipo}

Para implementação do FisioDRUM, utilizou-se o motor de jogos Unity 3D, por proporcionar uma interface intuitiva e interativa para desenvolvimento de games. Para capturar os movimentos realizados pelo paciente foi utilizado o dispositivo Kinect, sensor de movimentos escolhido devido a sua capacidade de reproduzir movimentos do corpo todo.

Por se tratar de aplicação de propósito específico, o escopo do jogo foi delineado a partir do estudo etnográfico e entrevistas com os profissionais das áreas de saúde e da música. Os principais requisitos levantados foram:

[RQ01].Reconhecer e mapear o corpo e os movimentos do paciente.

[RQ02] Utilizar técnicas de interação natural.

[RQ03] Apresentar interface interativa e de fácil aprendizado.

[RQ04] Oferecer recursos que orientem o usuário na realização dos exercícios.

[RQ05] Oferecer diferentes níveis de exercícios.

[RQ06] Possuir recurso que permita o acompanhamento da evolução do tratamento do paciente.

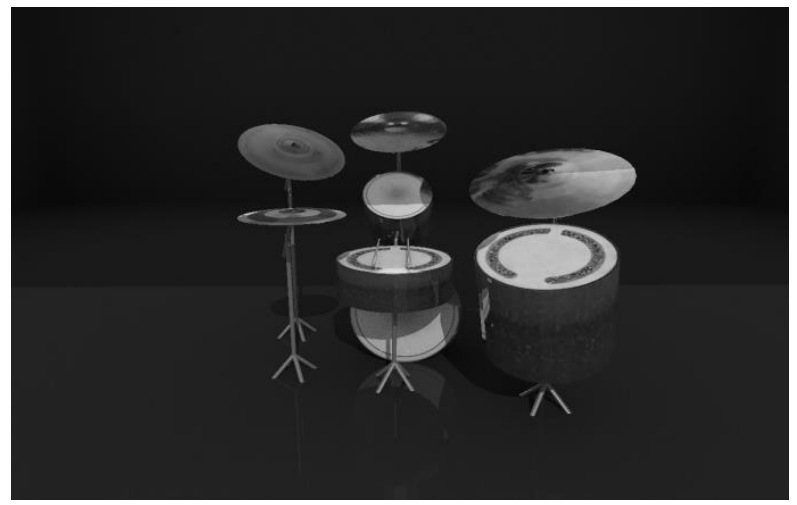

Figura 1: Tela Principal

O FisioDRUM, apresenta como cenário principal o instrumento musical bateria, como pode ser visto na figura 1 . O personagem do jogo é o paciente que terá que utilizar baquetas físicas para realizar os toques na bateria virtual. O sensor de movimentos Kinect faz a identificação automática dos movimentos, mapeando os movimentos das mãos e dos pés do paciente, permitindo uma interação natural entre o usuário e o instrumento, atendendo aos RQ01 e RQ02.

A interface é simples, apresentando apenas a bateria, com indicação visual da ordem dos exercícios a serem realizados por meio de um tutorial que orientará o paciente de forma intuitiva para que mesmo sem conhecimento do instrumento possa realizar os movimentos de forma fácil e agradável, de acordo com o RQ03 e RQ04. 
Oferece diferentes fases, que irão apresentar desde exercícios mais simples à exercícios mais complexos. Cada fase apresentará diferentes sequências de movimentos, diferentes ritmos e os instrumentos da bateria também serão incrementados na evolução de cada fase, atendendo o RQ05.

No final de cada fase será avaliado a força, amplitude, velocidade e precisão dos movimentos realizados nos toques dos instrumentos captados pelo sensor, permitindo avançar para a próxima fase ou repetir o exercício. O índice de desempenho deverá ser configurado pelo profissional de saúde de acordo com os perfis de usuários. A partir das avaliações citadas o jogo apresentará ainda relatórios para acompanhamento do tratamento, qual apresentará o desempenho e evolução do paciente atingindo o RQ06.

\section{Conclusão}

Com o presente trabalho foi possível identificar de forma preliminar a viabilidade técnica do jogo e a potencialidade de aplicação para o tratamento proposto, devido a colaboração e interesse dos profissionais envolvidos, que consideram importante o projeto. Além do interesse demonstrado também pelos pacientes desses profissionais.

Não foi encontrado nenhum jogo que utiliza o instrumento musical bateria como forma de tratamento fisioterapêutico, o que caracteriza um projeto inovador. É importante ainda destacar que para o tratamento da lesão indicada o jogo deverá ser utilizado com acompanhamento do fisioterapeuta, qual também será responsável pela indicação do nível do jogo para cada paciente. Como trabalho futuro sugere a realização de testes de aceitação, análise de viabilidade do protótipo e implementação do jogo.

\section{Referências}

Barnes, T., Encarnação, L. M. e Shaw, C. D. (2009). "Serious games". IEEE Computer Graphics and Applications. 29(2), p. 18-19.

Cardoso JP et al. (2008) "Construção de uma práxis educativa em informática na saúde para ensino de graduação". Ciênc. saúde coletiva, Rio de Janeiro, 13(1):283- 288, Fev.

Conde, G. (2013) "Gus conde, Bateroterapia", http:/gusconde.com/bateroterapia/, Fevereiro.

Johnson, W. L. (2007). "Serious use of a serious game for language learning”. Frontiers in Artificial Intelligence and Applications, p. 158, 67.

Leandro, J.A. et al (2006) "Promoção da Saúde Mental: música e inclusão social no Centro de Atenção Psicossocial de Castro/PR". Conexão UEPG.

Machado, L. S., Moraes, R.M., Nunes, F. (2009) "Serious games para saúde e treinamento imersivo." Porto Alegre: SBC, p. 31-60.

Schafer R.M. (1991) "Limpeza de Ouvidos". In: O Ouvido Pensante. SP: Fundação Editora da UNESP, p. 67-95

Storr A. (1992) "Music, Brain and Body. In: Music and the Mind.” New York: Free Press, p. 24- 48. 